\title{
The Analysis of the Key Problems about Traffic Accident Speed Identification Based on Braking Traces
}

\author{
Zhiwei Guan ${ }^{\mathrm{a}}$, Shaohua Wang ${ }^{\mathrm{b}}$, Weiqiang Liang ${ }^{\mathrm{c}}$, Mingfeng Zheng ${ }^{\mathrm{d}}$, Lin $\mathrm{Wu}^{\mathrm{e}}$, Yang $\mathrm{Liu}^{\mathrm{f}}$ and Zhenxing $\mathrm{Li}^{\mathrm{g}}$ \\ Tianjin University of Technology and Education, Tianjin, China \\ a guanzhiw5511@163.com, ${ }^{\mathrm{b}}$ shaohuawang2007@yahoo.com.cn, ${ }^{\mathrm{c}} 423$ qiang@sina.com \\ dtng418@sina.com, ${ }^{\mathrm{e}}$ wulin88@163.com, ${ }^{\mathrm{f}}$ danxingdaoly@126.com, ${ }^{\mathrm{g}}$ li_zhenxing_love@126.com \\ Corresponding Author: Weiqiang Liang
}

\begin{abstract}
In order to improve the impartiality and objectivity of judicial expertise, the key problems about traffic accident speed identification are analyzed and the speed of vehicle is calculated by using the braking performance test report with reference to the national standard and automobile theory. The automobile dynamics of driver braking process is analyzed, all kinds of key problems such as the braking distance, braking coordination time, braking speed, longitudinal sliding coefficient of adhesion are combined with the braking performance test report, and the method of determining the longitudinal sliding coefficient of adhesion is proposed, the instantaneous velocity before the collision is calculated. Finally, the method is used to calculate the speed of an actual case, and simulated in the software of PC-Crash, the results are consistent, verifying that the speed identification method is correct.
\end{abstract}

Keywords-Traffic Accident; Speed Identification; Braking Traces; PC-Crash

\section{INTRODUCTION}

The instantaneous speed identification of the vehicles in accidents is an important basis to determine traffic accident nature and responsibility for the accident, the accurate speed identification also reflects the impartiality and objectivity of judicial expertise. The common methods used to calculate the speed are brake drawing print, speed measurement through video, the amount of deformation method, pedestrian throw distance method, field experimentation, comprehensive evaluation ${ }^{[1],[2]}$. In the actual traffic accident identification process, some appraisers are not very clear for the braking process, which lead the mapping of the accident scene in the appraisal process and the speed identification are inaccurate. In addition, the braking performance of the traffic accident vehicle is often detected. The use of braking coordination time and MFDD (the average braking deceleration) in the braking performance test report can be deepened. The key issues of the braking distance, braking coordination time, braking speed, longitudinal sliding coefficient of adhesion for speed identification can be analyzed further based on the analysis of the driver's braking process, and the speed is calculated using the braking performance test report with reference to the national standard and automobile theory. Finally, this method is verified by a real case.

\section{The AUtOMOBILE DYNAMICS ANALYSIS OF THE TRAFFIC ACCIDENT VEHICLE BRAKING PROCESS}

The car's braking performance is directly related to vehicle traffic safety. It should master the braking characteristics when the vehicles involved in accidents in the process of moving around. The main detection index of automobile brake performance are braking force, braking distance, braking deceleration, braking coordination time and direction stability during braking ${ }^{[3],[4],[5]}$.

Combined with vehicle dynamics and the factors related to the accident vehicle brake, the accident vehicle braking process is shown in Fig. 1, including the following stages:

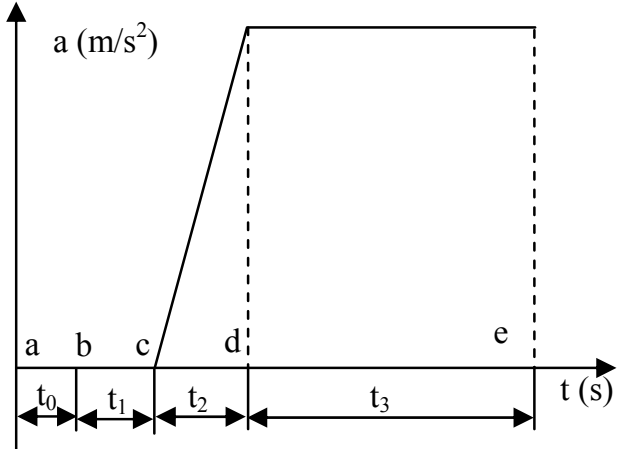

Fig. 1 Accident vehicle braking process

\section{A. The Reaction Time of Driver}

From the driver wants to stop when danger signal is founded (Fig. 1, point a) to the right foot stepped on the brake pedal, the elapsed time $t_{0}$ (Fig. 1 , point a to point $b$ ), is called driver reaction time. This length of time depends on whether the driver is concentrated on mind and the sensitivity degree of the operation, both of which depends on all kinds of factors such as the driver's age, personality, driving technology, the degree of fatigue, health status, road and weather conditions. The experiments show that $t_{0}$ is generally 0.3 to 1.0 seconds, an average value is 0.6 to 0.8 seconds ${ }^{[5]}$.

\section{B. Braking Device Reaction Time}

From the driver starts to depress the brake pedal, and overcome the free stroke of the braking pedal, retainer spring tension and the residual pressure of the braking device, to vehicle begins to decelerate (braking force) until the elapsed time (Fig. 1 point $\mathrm{b}$ to point $\mathrm{c}$ ), which known as the braking 
device reaction time or braking lag time, denoted by $t_{1}$. The length of $t_{1}$ depends on the form of brake actuating mechanism and the braking device. Reaction time of the hydraulic arresting apparatus is generally 0.03 to 0.05 seconds, the pneumatic braking system is in the range of 0.2 to 0.5 seconds $^{[5]}$.

\section{Braking Deceleration (Braking Force) Growth Time}

From the braking action generates as the driver depresses the pedal force, the braking force of the brake is increased from zero to the maximum value, and thus the braking deceleration from zero increased to maximum, the time required for this process is called braking deceleration (braking force) growth time $t_{2}$ (i.e. in Fig. 1 point $\mathrm{c}$ to point d). The length of $t_{2}$ is influenced not only by the contact surface condition of the brake shoe and brake drum, but also related to brake structure form, and depends on the speed and force size of the driver depresses the brake pedal. The hydraulic brake for $t_{2}$ is 0.15 to 0.2 seconds, and the pneumatic brake for $\mathrm{t}_{2}$ is 0.3 to 0.8 seconds ${ }^{[5]}$.

\section{Continuous Braking Time}

The amount of time the vehicles in accidents keep driving to completely stop in the case of the maximum deceleration is called continuous braking time $t_{3}$ (Fig. 1 point $\mathrm{d}$ to point $\mathrm{e})^{[5]}$. In $\mathrm{t}_{3}$ time, the braking deceleration is constant substantially.

Before and after the accident, the brake of the accident vehicle is generally not fully released before stopping. After reaching the test speed the tester depresses the brake pedal to the maximum until the vehicle stops in the road test, so the brake completely released time is not considered here. Make the parties detailed transcripts and do careful investigation of the scene traces during the calculation speed to determine whether the driver depresses the brake pedal to the maximum, in this way to take the braking distance is more scientific.

\section{Key PROBLEMS ANALysis}

\section{A. Braking Distance}

Braking distance is the distance of motor vehicles passing in the provision of initial velocity on a sudden braking from the foot touches the brake pedal (or hand touches the hand brake) until the motor vehicle stops. The braking distance $\mathrm{S}$ is:

$$
\mathrm{S}=\mathrm{S}_{1}+\mathrm{S}_{2}+\tilde{\mathrm{S}_{3}}
$$

Where $S_{1}$ is the distance traveled by the vehicle in time $t_{1}$, $S_{2}$ is the distance traveled by the vehicle in time $t_{2}, S_{3}$ is the distance traveled by the vehicle in time $t_{3}$.

In the $t_{2}$ time, braking deceleration is estimated as linear growth, ultimately vehicle braking distance $\mathrm{S}$ is calculated as:

$$
S=\frac{1}{3.6}\left(t_{1}+\frac{t_{2}}{2}\right) V_{0}+\frac{V_{o}^{2}}{25.92 \varphi \times g \times k}
$$

Where $\mathrm{S}$ is the braking distance, the unit is $\mathrm{m} ; \mathrm{t}_{1}$ is the braking device response time, the unit is $s ; t_{2}$ is the braking deceleration of growth time, the unit is $s ; V_{1}$ is the vehicle speed, the unit is $\mathrm{km} / \mathrm{h} ; \varphi$ is the longitudinal sliding coefficient of adhesion; $\mathrm{g}$ is the acceleration of gravity, the unit is $\mathrm{m} / \mathrm{s}^{2} ; \mathrm{k}$ is the coefficient of adhesion correction value.

Braking distance is equal to the sum of brake embossed and brake drawing print. In the accident identification, the brake embossed unclear, often take the brake drawing print instead of braking distance calculation speed, so the body smaller than the actual speed. At the same time, the brake drawing print also related to the operation skills of the driver, the vehicle braking performance, with or without ABS equipment, etc. ${ }^{[5]}$.

\section{B. Braking Coordination Time}

Braking coordination time is the time from beginning to depress the brake pedal in emergency braking to the braking deceleration(or braking force) reaches the average deceleration which meets the standard requirements, i.e. $75 \%$ of the MFDD(or specified in the standard braking force) in the braking performance test report ${ }^{[5]}$. Braking coordination time on the hydraulic brake car should not be greater than $0.35 \mathrm{~s}$, and for the pneumatic brake car should not be greater than $0.60 \mathrm{~s}$, for car trains, articulated buses and articulated trolleybuses should be no more than 0.80s. Braking coordination time is only a main portion of the brake action time, the actual vehicle speed is greater than the speed calculated by the braking coordination time.

\section{Braking Speed}

The braking speed is the initial braking speed $V$, in the $t_{1}$ time, the vehicle keeps the uniform motion and the initial braking speed remains the same; in the $t_{2}$ time, vehicle change for deceleration, this value variable speed decreases; in the $t_{3}$ time, uniform deceleration, this value constant decreases.

The distance here used to calculate the initial velocity is the brake drawing print, so the initial braking speed V can be estimated as follows:

$$
V=\frac{1}{2} \times \varphi \times g \times\left(t_{1}+\frac{t_{2}}{2}\right) \times k+\sqrt{2 \times \varphi \times g \times s \times k}
$$

Where $\mathrm{V}$ is the vehicle speed, the unit is $\mathrm{m} / \mathrm{s} ; \mathrm{g}$ is the acceleration of gravity, the unit is $\mathrm{m} / \mathrm{s}^{2} ; \mathrm{k}$ is the identification vehicle coefficient of adhesion correction value; $\varphi$ is the identification vehicle longitudinal sliding coefficient of adhesion; $\mathrm{S}$ is the brake drawing print, the unit is $\mathrm{m}$; $\mathrm{t}$ is the Braking coordination time, the unit is s.

\section{IDENTIFIED INSTANCE}

\section{A. Case Introduction}

2012 one day morning, on a highway, the road is dry asphalt pavement, pavement abrasion smaller, the weather is fine, a heavy-duty stake semi-trailer no-load is going to pull the goods traveling from south to north, electric bicycle is driving from north to southeast acrossing the road, heavyduty stake semi-trailer and the truck at ahead of the electric bicycle happened passing, and the electric bicycle isn't saw by driver, both sides dodge less then collided, cyclist was hit to fly, falling in front of the heavy-duty stake semi-trailer, the electric bicycle falling to the ground into the end of the 
heavy-duty stake semi-trailer tractor, and was being dragged slip some distance until the stop, the accident caused damage to the two machines and cyclist injured.

The central section of the heavy-duty stake semi-trailer front bumper is inward depression, electric bicycle front wheel is serious deformation, on the left side of the body there are many obvious tow slide traces, which is formed friction with the ground.

The schematic diagram of the traffic accident scene is shown in Fig. 2. Fig. $2 \mathrm{~A}$ is the heavy-duty stake semi-trailer final stop position, Fig. 2 B is the electric bicycle final stop position. By the traffic cop on the traffic accident scene investigation find that there are two brake drawing prints on the ground as shown in Fig. 2 printed a, b, long are $19.4 \mathrm{~m}$, brake drawing prints lasted from the starting point to the tractor rear wheels, which are basically formed by tractor rear wheels.

Tester does a road test for the heavy-duty stake semitrailer after the accident to braking performance using MBK01(III)B type brake performance tester at $31.5 \mathrm{~km} / \mathrm{h}$ initial braking speed in no-load condition, the braking coordination time is $0.530 \mathrm{~s}$, the MFDD value is $4 \mathrm{~m} / \mathrm{s}^{2}$, no deviation in the braking process.

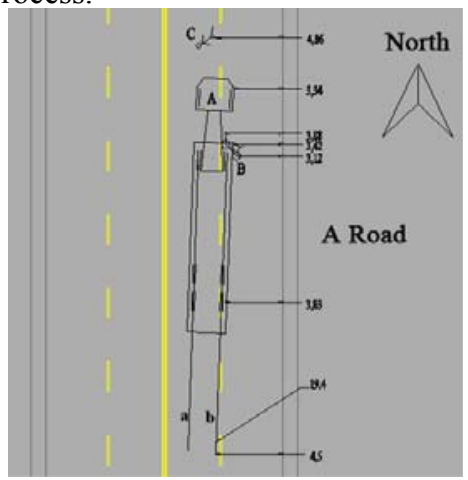

Fig. 2 The schematic diagram of the traffic accident scene

\section{B. Initial Braking Speed Calculation}

The determination of the longitudinal sliding coefficient of adhesion. The heavy-duty stake semi-trailer test result in the road test is unqualified, combined with scene traces these two brake drawing prints are mainly formed by tractor rear wheels, and accompanied by a small part of the trailer brake print. According to the B.2.2 of the GAT 643-2006 "the speed technical evaluation for vehicles involved in representative road accidents "[3], Select $\mathrm{k}$ value is $0.6^{[2]}$.

Braking deceleration Equation is:

$\mathrm{a}=\varphi \times \mathrm{g} \times \tilde{\mathrm{k}}$

According to the brake performance test result, where $\mathrm{a}=4 \mathrm{~m} / \mathrm{s}^{2}, \mathrm{~g}=9.8 \mathrm{~m} / \mathrm{s}^{2}$, substituted into the calculation, the longitudinal sliding coefficient of adhesion $\varphi$ is 0.68 .

The accident scene pavement is dry asphalt pavement, and the weather is fine, accident section pavement abrasion is small, so in accident the slip rate of the accident vehicle is 1 , the speed in road test is $31.5 \mathrm{~km} / \mathrm{h}$, so $\varphi=0.68$ comply with the B.3.1 of the GAT $643-2006$ "the speed technical evaluation for vehicles involved in representative road accidents "( in Table 1) $)^{[3]}$.
TABLE I. VEHICLE LONGITUDINAL SLIDING COEFFICIENT OF ADHESION REFERENCE VALUE

\begin{tabular}{|c|l|c|c|}
\hline \multirow{2}{*}{\multicolumn{2}{|c|}{ Pavement }} & \multicolumn{2}{|c|}{ Dry } \\
\cline { 3 - 4 } & $\begin{array}{c}\text { Less than } \\
\mathbf{4 8 k m} / \mathbf{h}\end{array}$ & $\begin{array}{c}\text { More than } \\
\mathbf{4 8 k m / h}\end{array}$ \\
\hline \multirow{3}{*}{$\begin{array}{c}\text { Asphalt } \\
\text { Pavement }\end{array}$} & New Road & $0.80 \sim 1.00$ & $0.60 \sim 0.70$ \\
\cline { 2 - 4 } & Pavement Abrasion Smaller & $0.60 \sim 0.80$ & $0.55 \sim 0.70$ \\
\cline { 2 - 4 } & Pavement Abrasion Larger & $0.55 \sim 0.75$ & $0.45 \sim 0.65$ \\
\cline { 2 - 4 } & Tar too many & $0.50 \sim 0.60$ & $0.35 \sim 0.60$ \\
\hline
\end{tabular}

Initial braking speed calculation. According to the initial braking speed calculation Eq. 3, the road test is in traffic accident road sections, so using the braking coordination time to replace the $\left(t_{1}+t_{2}\right) / 2$, that $\left(t_{1}+t_{2}\right) / 2=0.68, g=9.8 \mathrm{~m} / \mathrm{s}^{2}$, $\mathrm{k}=0.6, \mathrm{~S}=19.4 \mathrm{~m}$, so the initial braking speed $\mathrm{V}=48.61 \mathrm{~km} / \mathrm{h}$. Reference to Table 1 , the accident vehicle speed is slightly larger than $48 \mathrm{~km} / \mathrm{h}$, the $\varphi$ is also comply with the table 1 , so the initial braking speed is $48.61 \mathrm{~km} / \mathrm{h}$.

\section{The Verification of the Pc-Crash Software}

Loading heavy-duty stake semi-trailer, rider and electric bicycle model (Fig. 4), reference to deformation and road traffic accident scene diagram, put all kinds of parameters such as the heavy-duty stake semi-trailer, rider and electric bicycle final resting position and direction, heavy-duty stake semi-trailer's brake traces(Fig. 3) recorded at the road traffic accident scene diagram, rider, occupants, vehicle length, width, height, front overhang, track, wheelbase, quality, cargo, distance of C.G. from front, coefficient of friction, and the coefficient of restitution input software ${ }^{[6]}$.

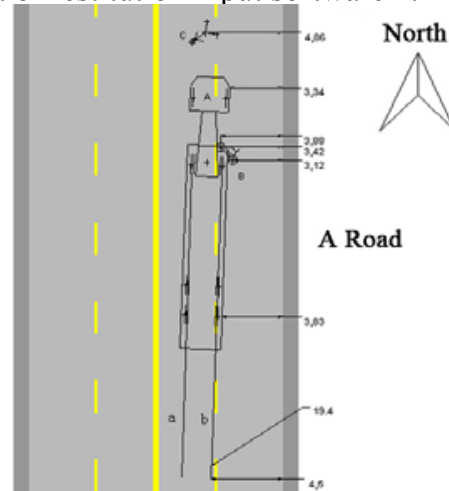

Fig. 3 The traffic accident scene diagram in pc-crash 


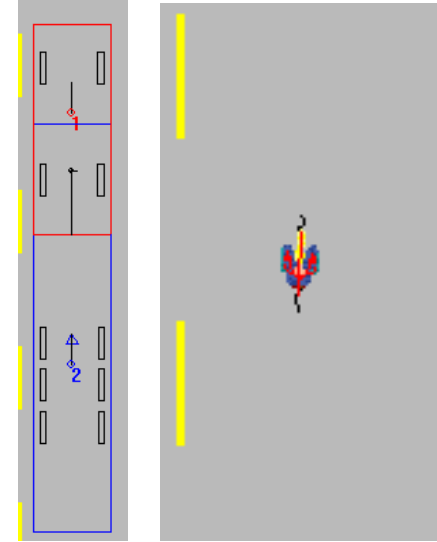

Fig. 4 Heavy-duty stake semi-trailer, rider and electric bicycle model
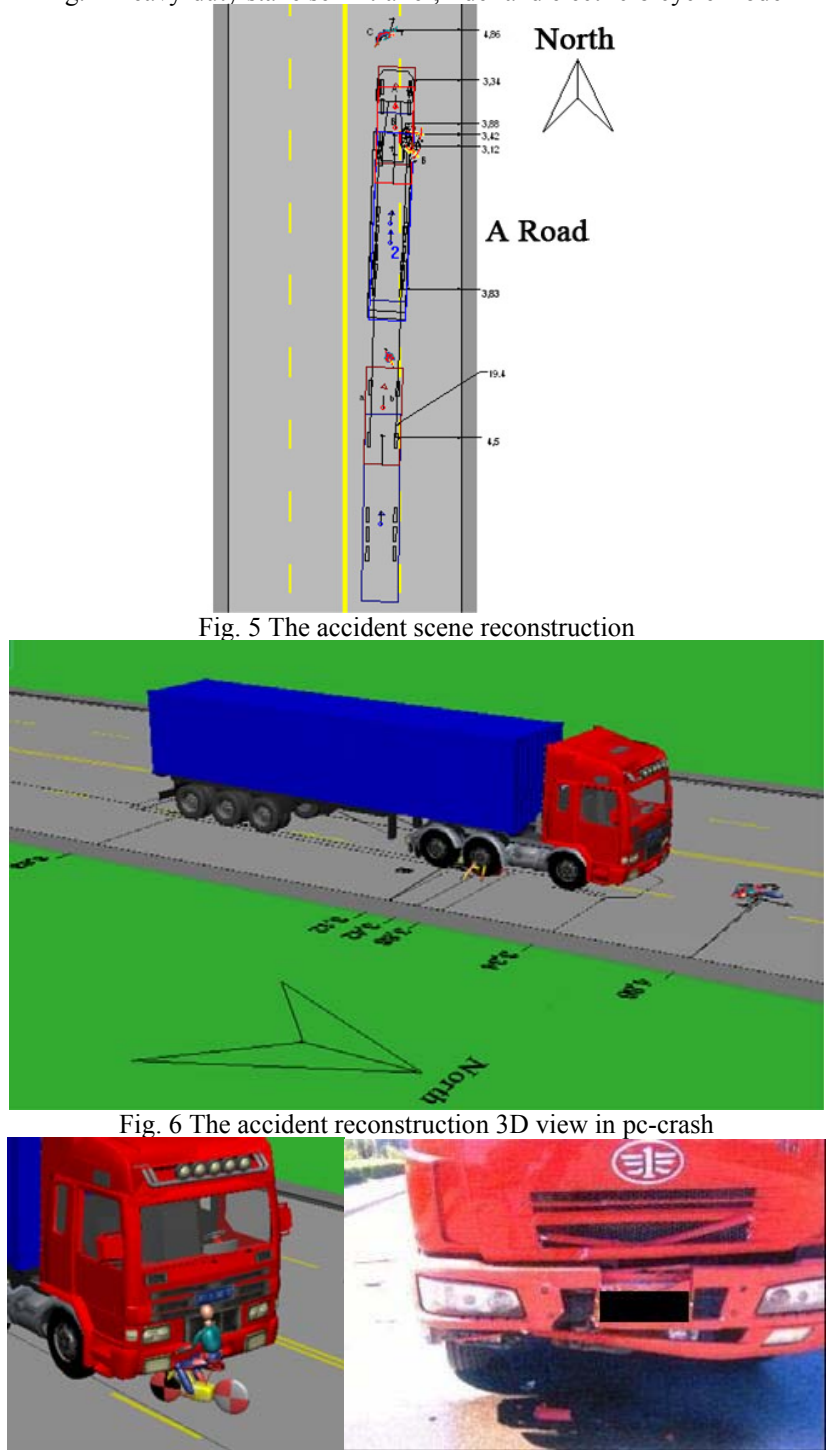

(a) Software simulated accident collision instantly position(b) The heavyduty stake semi-trailer front bumper

Fig. 7 Heavy-duty stake semi-trailer damaged part

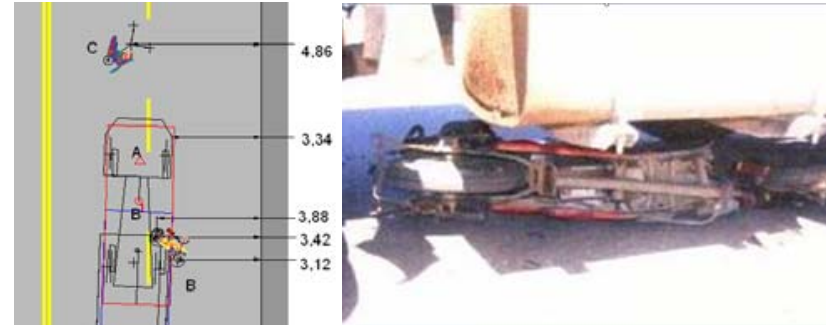

(a) Software simulation stop position (b) Electric bicycle scene photos Fig. 8 The rest position of the electric bicycle comparison

Input the accident sequences, the two machines location and direction, speed and so on to debug.

Comparing the rest position, the damaged parts and the tracks of the machines in the software with it in actual (Fig. $5,6,7,8)$, we can see the simulation results basically conform to the fact, and heavy-duty stake semi-trailer's speed before the collision is $47 \mathrm{~km} / \mathrm{h}$ to $49.5 \mathrm{~km} / \mathrm{h}$. So the Equation results in speed within its scope.

In summary, the speed references to Eq. 3 is reasonable.

\section{CONCLUSION}

All kinds of the key issues such as braking distance, coordination braking time, braking speed and the longitudinal sliding coefficient of adhesion are analyzed. The relationship between braking distance and brake drawing print is distinguished. The braking coordination time and MFDD are used in the braking performance test report, combining with the national standards, the longitudinal sliding coefficient of adhesion is determined, and then substituted into the Equation to calculate the instantaneous speed before a vehicle accident. Then simulation with the software Pc-crash, the results are consistent, verifying that the speed identification method is correct.

\section{ACKNOWLEDGMENT}

Thanks for the support by the scientific research key project of Ministry of Education (item number 209004).

\section{REFERENCES}

[1] Yin Peng. Research on traffic accident velocity and computation software development [D]. Shandong: Shandong University of Technology, 2010

[2] Yang Zhaoxiang, Li Guangxu. Speed identification method in traffic accident-using brake print formula to calculation speed [J]. Police Technology, 2007 (5) :13-16.

[3] GAT 643-2006, The speed technical evaluation for vehicles involved in representative road accidents [S]

[4] GB 7258-2004, Safety specifications for motor vehicles operating on roads [S].

[5] Yu Zhisheng. Automobile theory [M].Beijing: China Machine Press, 2000:77-81

[6] Zou Tiefang, Yu Zhi. Car-pedestrian accident reconstruction based on Pc-Crash [J]. Journal of Vibration and Shock, 2011 (3) :215-219. 